\title{
A comparison of interpupillary distances between Turkish and Azerbaijani populations
}

Ibrahim Sahbaz ( $\nabla$ ibrahim.sahbaz@uskudar.edu.tr)

Department of Ophthalmology, Üsküdar University Faculty of Medicine, Istanbul, Turkey

Research article

Keywords: interpupillary distance, ethnicity, forensic medicine, Turkey, Azerbaijan, anthropometry

Posted Date: May 5th, 2020

DOl: https://doi.org/10.21203/rs.3.rs-20461/v1

License: (9) This work is licensed under a Creative Commons Attribution 4.0 International License. Read Full License 


\section{Abstract}

Background: Differences in far interpupillary distance (IPD) in Turkish and Azerbaijani adults of the same ethnic background from different age groups were examined to investigate the effects of ethnicity, genetics, geography, and environmental factors on IPD.

Methods: A total of 1,400 healthy individuals aged $\geq 18$ years were enrolled. The far IPD of each individual was determined in both communities. IPD data for 700 subjects in Azerbaijan and 700 subjects in Turkey was analyzed. Males and females were divided into six age ranges: $18-24,25-34,35-44,45-$ $54,55-64$, and $\geq 65$ years. Far IPD data in Turkey and Azerbaijan was collected using two types of autorefractometers: Topcon RM 8800 and Topcon TRK-2P.

Results: The mean age of the 700 subjects in Turkey was $44.5 \pm 17.6$ years. The mean IPD was $62.1 \pm 3.7$ $\mathrm{mm}$. The mean IPD in females was $61 \mathrm{~mm}$, which was less than males $(63 \mathrm{~mm})(P<0.05)$. The mean age of the 700 Azerbaijani subjects was $44.0 \pm 15.6$ years. The mean IPD of the subjects was $65.0 \pm 3.1$ $\mathrm{mm}$. The mean IPD $(64 \mathrm{~mm})$ in females was significantly lower than the mean IPD $(66 \mathrm{~mm})$ in males $(\mathrm{P}<$ 0.05). Differences in IPD between age groups in both communities were statistically significant $(P<$ 0.05). The mean IPD in all age groups in the Azerbaijani population was greater than that of the Turkish population. Compared with other ethnic groups, the mean IPD in the Azerbaijani population was remarkably high.

Conclusions: When mean far IPD values in individuals aged $\geq 18$ years in the Azerbaijani and Turkish populations were compared, statistically significant differences were observed. In Azerbaijani Turks, mean IPD values in both males and females were greater than those observed in the Turkish population in all age groups. The mean IPD values of the Azerbaijani population were greater than those of other ethnic groups when classified by both age and sex. As well as ethnicity, geographical and environmental factors influenced far IPD values.

\section{Background}

The normal distribution of craniofacial anthropometric measurements in communities shows some differences. Recognition of normal facial anthropometric data is important as it is used in many applications [1]. Interpupillary distance (IPD) is an oculofacial parameter that is routinely measured in ophthalmology. The distance between the center of one pupil and the other on the line of sight (i.e., IPD) is an important clinical measure in ophthalmology $[2,3]$.

Craniofacial and ocular biometric measurements are frequently used in ophthalmology; optometry; opticianry; plastic surgery; forensic medicine; mouth, teeth, and facial surgeries; and genetic, anthropological, and ethnic research. IPD is an important parameter that is related to the eyes. Ethnicity, genetics, gender, age, and environmental and geographic differences are thought to be determining factors in facial anthropometric dimensions $[4,5]$. 
In craniofacial anthropometric measurements, research shows that the largest differences exist in the orbitonasal region [1]. Even among individuals of the same ethnicity, differences in IPD depend on age and gender. Another factor is the effect of geographical conditions on IPD [4]. Identifying differences in IPD between Turkish and Azerbaijani populations of the same ethnic background may provide a contribution to knowledge in this area. This study, which measures IPD in Turkish and Azerbaijani populations, is one of the few studies showing that geographical factors can be an effective factor in this regard.

Measurement of IPD is an integral part of the optometric examination and one of the most important components of the optical design process [6]. IPD is one of the important reference points in the horizontal plane of the head, and it is used in facial, mouth, and dental surgery [7].

Different methods can be used to measure IPD; some are manual, while others are automatic. Threedimensional (3D) photographic measurements can also be produced. Manual measurements use a range of tools and techniques such as rulers, as shown in Fig. 1.

Another commonly used method that can be used to measure IPD is the digital pupillometer (Fig. 2). Other optical tools that can be used to measure IPD include 3D digital photoshoots, the Optical Vernier PD Ruler (Fig. 3), and infrared eye trackers [8, 9, 10, 11].

Digital measurement devices are commonly used today. These devices measure eye refraction defects. We used digital autorefractometers in our study, as shown in Fig. 4.

IPD measurements are used in different fields of study including plastic surgery, oral and dental applications, forensic science, genetic science, anthropology, facial surgery, optical devices, and the contact lens and glasses industries. Ethnicity is one factor that influences differences in IPD in humans, but IPD may also differ depending on one's geographic location. IPD varies throughout life, starting from birth. In the period of growth and development, a rapid increase in IPD is observed. Changes in IPD vary by age, ethnicity, and gender $[12,13]$.

There are two definitions of IPD; anatomical IPD and physiological IPD are measured with units of distance. The difference between the two measurements is negligible [14]. In addition, two separate measurements can be made: far IPD and close IPD. In the present study, far IPD measurements were evaluated in line with previous studies.

\section{Methods}

A total of 1,400 participants of Turkish ethnic origin residing in Turkey and Azerbaijan were included in the study. Eye examination data from 700 subjects at Dunya Goz Hospital in Istanbul, Turkey; and 700 subjects at Dunya Goz Hospital in Baku, Azerbaijan, were analyzed. The necessary permissions were obtained from the ethics committee of Uskudar University and studies were carried out in accordance 
with the tenets of the Declaration of Helsinki (B.08.06.YÖK.2.ÜS.0.05.0.06/2018/604). Written and verbal informed consent was obtained from all participants.

The ethnic origin and family tree of each individual were assessed; all participants were confirmed to be of Turkish origin. In addition, adults aged $\geq 18$ years were included in the study. Individuals with facial pathologies or previous surgery were excluded. Those with congenital or acquired pathologies of the head and face (e.g., macrocephaly) were evaluated within the exclusion criteria.

A total of 1,400 participants underwent a complete eye examination, which was carried out by the same ophthalmologist in each case. Eye measurements were confirmed twice. Far IPD measurements were performed using two autorefractometers: Topcon RM 8800 and Topcon Auto Kerato-Refractor/Tonometer TRK-2P.

During IPD measurements, care was taken to ensure that participants' sitting positions were appropriate. Particular attention was paid to ensure that the head and chin were correctly positioned during the measurement. The IPD values measured using autorefractometers comprised far IPD measurements.

The data found in Turkey and Azerbaijan by separating the males and females. Data from the two groups was divided into six groups by age range: $18-24,25-34,35-44,45-54,55-64$, and $\geq 65$ years.

The mean, standard deviation, median (lowest and highest), frequency, and ratio were used as descriptive statistics of the data. Distribution of the variables was measured using the Kolmogorov-Smirnov test. To analyze quantitative independent data, the Mann-Whitney $U$ test was applied. The chi-squared test was used to analyze qualitative independent data. SPSS 22.0 (IBM Corporation, Armonk, NY, USA) was used to perform statistical analyses. A P value of $<0.05$ was considered statistically significant.

\section{Results}

In the present study, which applied exclusion criteria for subject selection, 1,400 randomly selected subjects were enrolled. Of the 1,400 subjects, 733 (52.4\%) were female and 667 (47.6\%) were male.

The mean age of the subjects was $17.6 \pm 44.5$ years for the Turkish population and $44.0 \pm 15.6$ years for the Azerbaijani population; the overall age range was $18-80$ years. There was no significant difference in the mean age of males and females between the Turkish and Azerbaijani populations $(P=0.363)$. Mean IPD in the Turkish population was $62.1 \pm 3.7 \mathrm{~mm}$ (median $=62.0 \mathrm{~mm}$ ), while mean IPD in the Azerbaijani population was $65.0 \pm 3.1 \mathrm{~mm}$ (median $=65.0 \mathrm{~mm}$ ).

Table 1 and Table 3 show age, sex, and IPD measurements. In 1,400 subjects, IPD was significantly greater in males compared with females in both populations $(P=0.000)$. Mean IPD values by age group are shown in Table 2.

Table 1 


\begin{tabular}{|c|c|c|c|c|c|c|c|c|}
\hline & & \multicolumn{3}{|c|}{ Turkish population } & \multicolumn{3}{|c|}{ Azerbaijani population } & \multirow[t]{2}{*}{ P-value } \\
\hline & & \multicolumn{2}{|c|}{ Mean age \pm SD } & \multirow{2}{*}{$\begin{array}{l}\text { Median } \\
46.0\end{array}$} & \multicolumn{2}{|c|}{ Mean age \pm SD } & \multirow{2}{*}{$\begin{array}{l}\text { Median } \\
44.0\end{array}$} & \\
\hline Overall & & $44.5 \pm$ & \pm 17.6 & & $44.0 \pm$ & 15.6 & & 0.716 \\
\hline \multirow[t]{6}{*}{ Age (years) } & $18-24$ & 126 & $34.1 \%$ & & 125 & $33.8 \%$ & & 0.127 \\
\hline & $25-34$ & 127 & $34.3 \%$ & & 129 & $34.9 \%$ & & \\
\hline & $35-44$ & 95 & $25.7 \%$ & & 119 & $32.2 \%$ & & \\
\hline & $45-54$ & 133 & $35.9 \%$ & & 151 & $40.8 \%$ & & \\
\hline & $55-64$ & 126 & $34.1 \%$ & & 103 & $27.8 \%$ & & \\
\hline & $\geq 65$ & 93 & $25.1 \%$ & & 73 & $19.7 \%$ & & \\
\hline \multirow[t]{2}{*}{ Sex } & Female & 375 & $101.4 \%$ & & 358 & $96.8 \%$ & & 0.363 \\
\hline & Male & 325 & $87.8 \%$ & & 342 & $92.4 \%$ & & \\
\hline
\end{tabular}

${ }^{\mathrm{m}}$ Mann-Whitney U test ${ }^{\mathrm{X}}{ }^{\mathrm{c}}$ chi-squared test

Table 2

\begin{tabular}{|c|c|c|c|c|c|c|c|c|}
\hline & & \multicolumn{3}{|c|}{ Turkish population } & \multicolumn{3}{|c|}{ Azerbaijani population } & \multirow{2}{*}{$\overline{\text { P-value }^{m}}$} \\
\hline & & \multicolumn{2}{|c|}{ Mean \pm SD } & \multirow[t]{2}{*}{$\overline{\text { Median }}$} & \multicolumn{2}{|c|}{ Mean \pm SD } & \multirow[t]{2}{*}{ Median } & \\
\hline \multicolumn{7}{|l|}{$I P D(\mathrm{~mm})$} & & \\
\hline Overall & & 62.1 & \pm 3.7 & 62.0 & 65.0 & \pm 3.1 & 65.0 & 0.000 \\
\hline $18-24$ & & 60.3 & \pm 3.9 & 60.0 & 65.8 & \pm 2.5 & 65.0 & 0.000 \\
\hline $25-34$ & & 60.7 & \pm 3.0 & 61.0 & 66.0 & \pm 3.1 & 66.0 & 0.000 \\
\hline $35-44$ & & 63.2 & \pm 3.3 & 63.0 & 64.6 & \pm 2.9 & 65.0 & 0.001 \\
\hline $45-54$ & & 63.4 & \pm 3.6 & 64.0 & 64.5 & \pm 3.4 & 64.0 & 0.004 \\
\hline $55-64$ & & 62.7 & \pm 3.6 & 63.0 & 64.6 & \pm 3.5 & 65.0 & 0.000 \\
\hline Age $\geq 65$ & & 62.4 & \pm 3.6 & 62.0 & 64.2 & \pm 2.7 & 64.0 & 0.001 \\
\hline \multirow[t]{2}{*}{ Sex } & Female & 61.1 & \pm 3.4 & 61.0 & 64.1 & \pm 2.9 & 64.0 & 0.000 \\
\hline & Male & 63.1 & \pm 3.7 & 63.0 & 66.0 & \pm 3.1 & 66.0 & 0.000 \\
\hline
\end{tabular}

m Mann-Whitney U test

Table 3 


\begin{tabular}{llcccc}
\hline Overall & \multicolumn{1}{c}{18} & -80 & 45.0 & 44.3 & \pm 16.6 \\
\hline Age (years) & $18-24$ & & 251 & $17.9 \%$ \\
& $25-34$ & & 256 & $18.3 \%$ \\
\cline { 2 - 5 } & $35-44$ & & 214 & $15.3 \%$ \\
\cline { 2 - 5 } & $45-54$ & & 284 & $20.3 \%$ \\
\cline { 2 - 5 } & $55-64$ & & 229 & $16.4 \%$ \\
\hline Sex & Female & & 166 & $11.9 \%$ \\
\cline { 2 - 5 } & Male & & 733 & $52.4 \%$ \\
\hline IPD (mm) & & & 667 & $47.6 \%$ \\
\hline
\end{tabular}

The age and gender distribution of the patients did not differ significantly between the Turkish and Azerbaijani populations $(p>0.05)$ (Table 2$)$.

When the mean IPD of the Azerbaijani population was compared with the mean IPD of the age group, for all age groups (18-24, 25-34, 35-44, 45-54, 55-64, and $\geq 65$ years), the IPD was significantly greater in the Azerbaijani population $(p \otimes 0.05)$ than the Turkish population. When grouped by gender, the IPD was significantly greater $(p \otimes 0.05)$ in females in the Azerbaijani population compared with females in the Turkish population. In males, the IPD in the Azerbaijani population was significantly greater $(p \otimes 0.05)$ compared with the Turkish population (Table 3).

In the present study, the mean IPD in every age and sex group in subjects in the Azerbaijani population ( $\geq 18$ years) was significantly greater than the mean IPD in the Turkish population. 


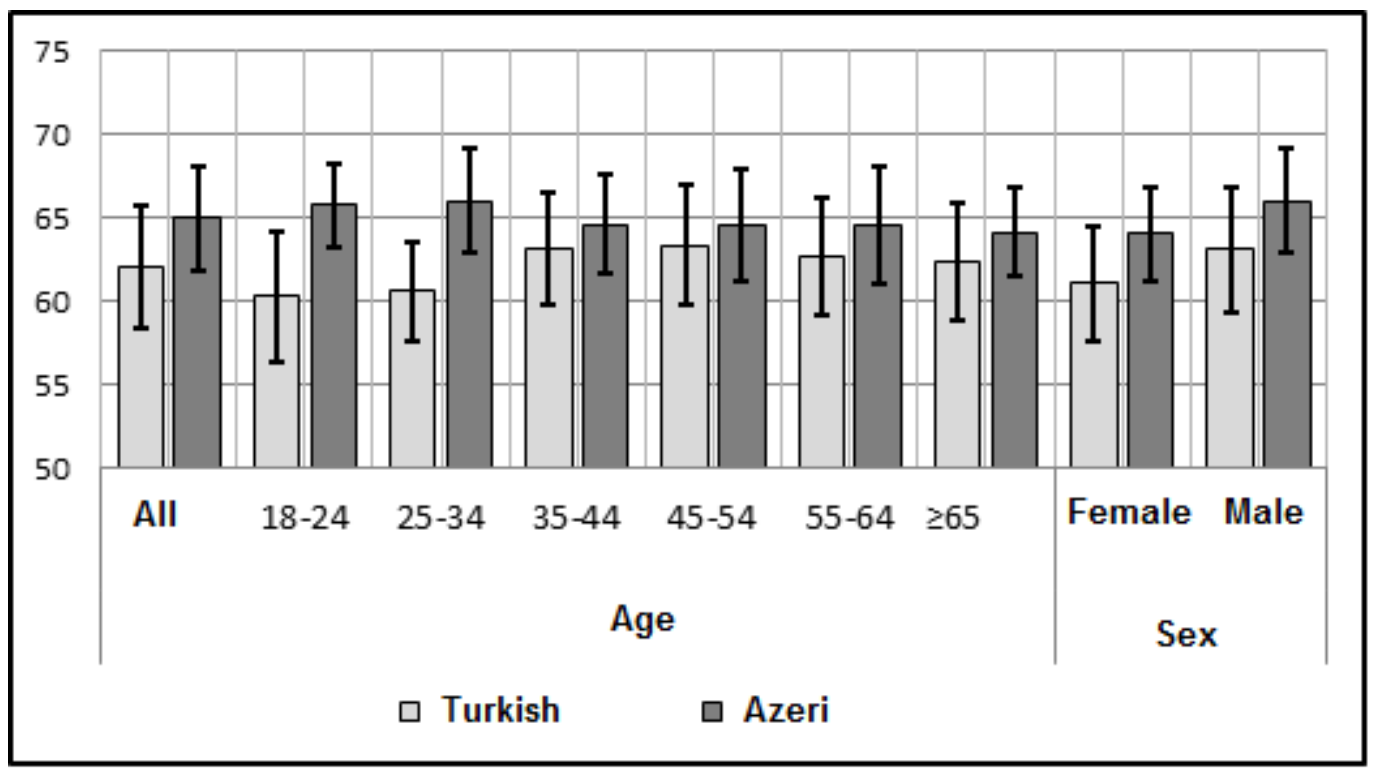

When considering age-related differences in IPD, changes in IPD in six different age groups in the Turkish population were as follows. IPD gradually increased by $3.1 \mathrm{~mm}$ in the $18-54$-year age group. A reduction in IPD was observed with an increase in age; specifically, a reduction in IPD of $1.0 \mathrm{~mm}$ was observed in the 45-65-year age group. In the Azerbaijani population, there was an increase of $0.2 \mathrm{~mm}$ in age-related IPD in the 18-34-year age group, and a decrease of $1.5 \mathrm{~mm}$ in the 25-34-year and 45-54-year age groups. IPD decreased by $0.4 \mathrm{~mm}$ in the $55-64$-year and $\geq 65$-year age groups.

\section{Discussion}

Normally distributed facial anthropometric and ocular biometric measurements by age and gender are used to produce industrial and medical prostheses and devices for the face and eyes; they are also used in medical and surgical applications [15].

Normal IPD, which is one of the facial anthropometric measurements, is one of the important measurement points on the face; it is considered in genetics, anthropology, forensic medicine, ophthalmology, and dental and facial surgeries [16].

Different methods can be used to measure IPD when carrying out eye examinations. IPD can be determined using manual and automatic measurements. IPD measurements are based on the values found when looking away. It performs both refraction and IPD distance measurements in autorefractometers in eye examinations. In our study, an autorefractometer was used to obtain far IPD measurements.

In both the Turkish and Azerbaijani populations, IPD values were greater in males than in females, which is in agreement with previously published studies. In a study conducted in adult males and females in Iran, the mean IPD in males was $63.6 \pm 3.9 \mathrm{~mm}$, while the mean IPD in females was $61.1 \pm 3.5 \mathrm{~mm}$ [12]. 
In another study conducted in Pakistan, the mean IPD values reported in adults were $62.7 \pm 6.861 \mathrm{~mm}$ in males and $60.7 \pm 5.03 \mathrm{~mm}$ in females. In the same study, the mean IPD values of different ethnic groups were $62.5 \pm 6.7 \mathrm{~mm}$ (Urdu), $60.9 \pm 5.5 \mathrm{~mm}$ (Sindhi), $61.2 \pm 6.5 \mathrm{~mm}$ (Punjabi), and $62.5 \pm 6.6 \mathrm{~mm}$ (Pathan) [17].

In a study that enrolled Malay and Chinese participants, the mean IPD values were $62.44 \pm 2.66 \mathrm{~mm}$ in adult females and $66.03 \pm 2.96 \mathrm{~mm}$ in adult males (Malay), and $61.31 \pm 2.76 \mathrm{~mm}$ in adult females and $64.37 \pm 2.59 \mathrm{~mm}$ in adult males (Chinese)[9]. Murray et al. conducted a study on 416 subjects in the USA; the mean IPD value was $65.32 \mathrm{~mm}$ in males and $61.53 \mathrm{~mm}$ in females [10]. In another study conducted in Nepal, the mean IPD values were $61.92 \pm 5.85 \mathrm{~mm}$ (Arians) and $57.50 \pm 7.23 \mathrm{~mm}$ (Mongoloids) (18). In a study conducted in India, the mean IPD was $61.1 \mathrm{~mm}$ in males and $58.2 \mathrm{~mm}$ in females [19]. In a study conducted in Nigeria, it was emphasized that racial factors and environmental factors may influence ocular biometric characteristics, which differ between societies [20]. Facial anthropometric differences were statistically significant in a study conducted between four different ethnic groups in the USA, including White, African-American, Hispanic, and Asian [4].

Considering the comparison of the IPD results, the mean IPD of the Azerbaijani population was greater than that of the Turkish population and was also generally greater than that of other populations $[9,10$, $12,17,19,21]$.

\section{Conclusion}

To the best of our knowledge, the present study is the first oculofacial anthropometric study conducted on Turkish and Azerbaijani populations to compare IPD. Significant differences were observed, which were greater in all age and sex groups. Although both populations were of the same ethnic background, it is thought that differences in geography may have contributed to the observed differences in IPD.

Although ethnicity, age, and gender influence IPD, geographic differences may also contribute. Our study shows normal IPD values by both age and gender in both Turkish and Azerbaijani populations. This data may contribute to future studies, particularly those carried out in the sectors of surgery and optometrics.

It is noteworthy that the mean IPD value in the Azerbaijani population was greater than that observed in the Turkish population, particularly in Turkish females; and greater than many other ethnic groups, as reported by previous studies. Further studies should be conducted in different ethnic groups in the future to clarify the findings of the present study.

\section{Abbreviations}

IPD: Interpupillary distance

\section{Declarations}


-Ethics approval and consent to participate: The study followed the tenets of the Declaration of Helsinki and has been approved by the local ethics committee. Written informed consent was obtained from all participants.

Ethics Committee of Üsküdar University (SAYI: B.08.6.YÖK.2ÜS.0.05.0.06/2018/604)

-Consent for publication: Not applicable

-Availability of data and material: The data in this study could be obtained from the corresponding author upon reasonable request.

-Competing interests: The authors declare that they have no competing interests

-Funding: Non-financial

-Authors' contributions: Corresponding author. Author read and approved the final manuscript.

-Acknowledgements: Not applicable

\section{References}

1. Virdi SS, Wertheim D, Naini, FB. Normative anthropometry and proportions of the Kenyan-African face and comparative anthropometry in relation to African Americans and North American Whites. Maxillofacial plastic and reconstructive surgery 2012; 41 (1): 9. doi:10.1186/s40902-0190191-7.

2. Borish IM. Clinical Refraction. $3^{\text {rd }}$ Chicago, ILL, USA. Professional Press; 1975 . pp. 424-428.

3. Brown, WL. Interpupillary distance. eds. Eskridge JB, Amos JF, and Bartlett JD. In: Clinical Procedures in Optometry. Philadelphia, PA, USA. JB Lippincott; 1991. pp. 39-52.

4. Ziqing Zhuang, Douglas Landsittel, Stacey Benson, Raymond Roberge, Ronald Shaffer, Facial Anthropometric Differences among Gender, Ethnicity, and Age Groups, The Annals of Occupational Hygiene, Volume 54, Issue 4, June 2010, Pages 391-402, https://doi.org/10.1093/annhyg/meq007

5. Schmidt P, Kempin R, Langner S, Beule A, Kindler S et al. Association of anthropometric markers with globe position: a population-based MRI study. PLoS One 2019; 14 (2): e0211817. doi:

10.1371/journal.pone.0211817. PMID: 30730926; PMCID: PMC6366780.

6. Holland BJ, Siderov J. Repeatability of measurements of interpupillary distance. Ophthalmic and Physiological Optics 1999; 19: 74-78. doi:1046/j.1475-1313.1999.00400.x.

7. Kattan EE, Kattan ME, Elhiny OA. A New Horizontal Plane of the Head. Open Access Maced J Med Sci 2018; 6 (5): 767-771. doi: 10.3889/oamjms.2018.172. PMID: 29875843; PMCID: PMC5985866.

8. Chihargo S. CRC1: Iris Positioning Technique by Using Optical Vernier Interpupillary Distance Ruler on the Custom Ocular Prosthesis. J Indian Prosthodont Soc 2018; 18 (Suppl. 1): S35. doi: 10.4103/0972-4052.244655. PMID: 30532453; PMCID: PMC6238481. 
9. Lu TY, Kadir K, Ngeow WC, Othman SA. The Prevalence of Double Eyelid and the 3D Measurement of Orbital Soft Tissue in Malays and Chinese. Sci Rep 2017; 7(1): 14,819. doi: 10.1038/s41598-01714829-4. PMID: 29093554; PMCID: PMC5665901.

10. Murray NP, Hunfalvay M, Bolte T. The Reliability, Validity, and Normative Data of Interpupillary Distance and Pupil Diameter Using Eye-Tracking Technology. Transl Vis Sci Technol 2017; 6 (4): 2. doi: 10.1167/tvst.6.4.2. PMID: 28685104; PMCID: PMC5497600.

11. Jayaratne YS, Deutsch CK, Zwahlen RA. Normative findings for periocular anthropometric measurements among Chinese young adults in Hong Kong. Biomed Res Int 2013: 821428. doi: 10.1155/2013/821428. Epub 2013 Jul 17. PMID: 23957005; PMCID: PMC3730197.

12. Fesharaki H, Rezaei L, Farrahi F, Banihashem T, Jahanbkhshi A. Normal interpupillary distance values in an Iranian population. J Ophthalmic Vis Res 2012; (3): 231-4. PMID: 23330061; PMCID: PMC3520592.

13. Surendra B, Patil SM, Kale MM, Nishant K, Jaiswal S. Anthropometry of the Eyelid and Palpebral Fissure in an Indian Population. Aesthetic Surgery Journal, 2011; 31 (3): 290294. https://doi.org/10.1177/1090820X11398475.

14. Osuobeni EP, Al-Fahdi M. Differences between anatomical and physiological interpupillary distance. J Am Optom Assoc 1994; 65 (4): 265-71.

15. Arenas, E., Muñoz, D., Matheus, E., \& Morales, D. (2014). Nasopupillary asymmetry. TheScientificWorldJournal, 2014, 347826. https://doi.org/10.1155/2014/347826

16. Tripathi S, Singh RD, Chand P, Kumar L, Singh GK. A study to correlate various facial landmarks with intercanine distance. Indian J Dent Res 2018; 29: 440-4.

17. Hayat N, Alkhairy S, Cheema A, Ehsan M, Khan MA. Normal interpupillary, inner canthal distance and outer canthal distance in a normal population of Pakistan. Pak J Med Sci 2019; 35 (1): 50-54. doi: 10.12669/pjms.35.1.288. PMID: 30881395; PMCID: PMC6408655.

18. Mishra MK, Singh RK, Suwal P, Parajuli PK, Shrestha P et al. A comparative study to find out the relationship between the inner inter-canthal distance, interpupillary distance, inter-commissural width, inter-alar width, and the width of maxillary anterior teeth in Aryans and Mongoloids. Clin Cosmet Investig Dent 2016; 8: 29-34. doi: 10.2147/CCIDE.S87837. PMID: 26955292; PMCID: PMC4772945.

19. Ladda R, Kasat VO, Bhandari AJ. A new technique to determine vertical dimension of occlusion from anthropometric measurement of interpupillary distance. J Clin Exp Dent 2014; 6 (4): e395-9. doi: 10.4317/jced.51671. PMID: 25593663; PMCID: PMC4282908.

20. Badmus SA, Ajaiyeoba Al, Adegbehingbe BO, Onakpoya OH, Adeoye AO et al. Relationship between Refraction, Anthropometrics, and Educational Status in a Nigerian Young Adult Population. Middle East Afr J Ophthalmol 2018; 25 (1): 30-34. doi: 10.4103/meajo.MEAJO_16_16. PMID: 29899648; PMCID: PMC5974815.

21. Mishra MK, Singh RK, Suwal P, Parajuli PK, Shrestha P et al. A comparative study to find out the relationship between the inner inter-canthal distance, interpupillary distance, inter-commissural width, 
inter-alar width, and the width of maxillary anterior teeth in Aryans and Mongoloids. Clin Cosmet Investig Dent 2016; 8: 29-34. doi: 10.2147/CCIDE.S87837. PMID: 26955292; PMCID: PMC4772945.

\section{Figures}

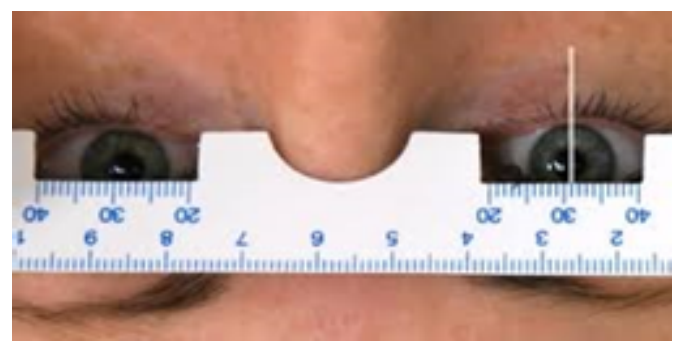

\section{Figure 1}

Measuring IPD using a ruler

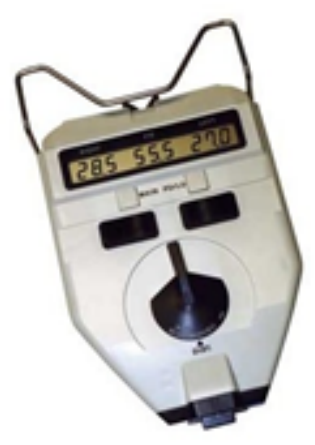

Figure 2

\section{Pupillometer}

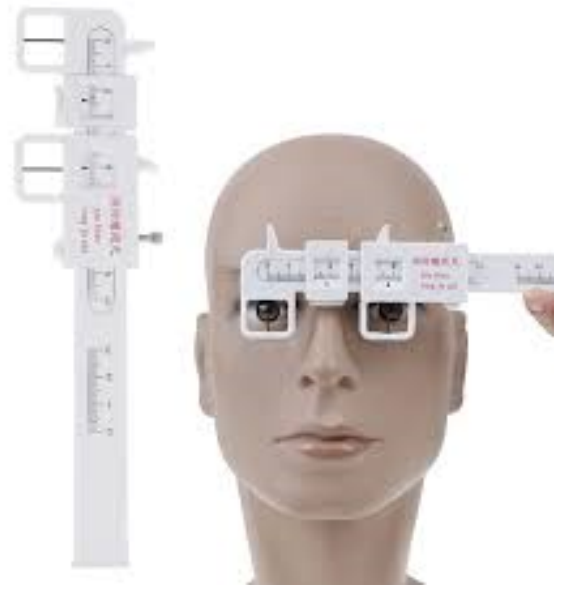

Figure 3

Optical Vernier PD Ruler 


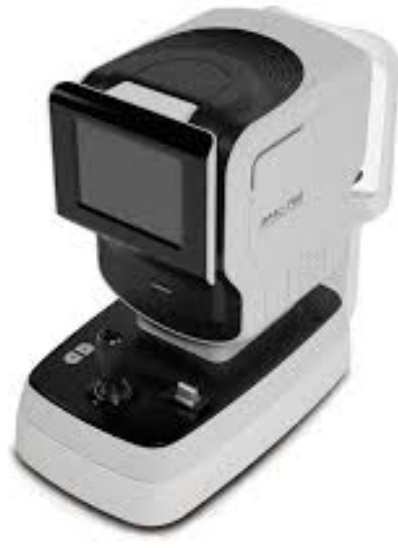

Figure 4

Autorefractometer 